\title{
DESIGNACION DE JUEZ DE POLICIA LOCAL CON INVESTIDURA REGULAR
}

\author{
Hugo Caldera Delgado \\ Profesor Titular de Derecho Administrativo \\ Facultad de Derecho - Universidad de Chile
}

\section{SUMARIO}

1. Introducción. 2. El requisito constitucional de la investidura regular. 3. Efectos jurídicos de la falta de investidura regular. 4. Normas jurídicas que rigen el nombramiento de Juez de Policía Local. 4. Organos que deben intervenir en la designación de Juez de Policía Local. 4.1.1. Organos Municipales "esenciales" que deben intervenir en la designación de Juez de Policía Local. 4.1.2. Atribuciones genéricas que la Constitución Política otorga al Concejo. 5. Jurisprudencia de los Tribunales Superiores de Justicia. 5.1. Problema suscitado en relación con Recurso de Protección ante la I.CAP. de Iquique. 5.2. Problema suscitado por la designación de Juez de Policía Local de la I. Municipalidad de Quilicura. 6. Conclusión.

\section{INTRODUGGION}

El nombramiento en el cargo de Juez de Policía Local ha producido dificultades jurídicas, en relación al procedimiento que debe efectuarse a nivel municipal. El problema surge a consecuencia de la errónea interpretación del artículo $4^{\circ}$ del texto refundido de la Ley № 15.231 sobre "Organización y atribuciones de los Juzgados de Policía Local", que dice: "Los Jueces de Policía Local serán designados por la Municipalidad que corresponda". Dicha norma ha sido equivocadamente interpretada, al entender que dicha disposición se refiere, exclusivamente, al Alcalde, con exclusión de la intervención y del acuerdo del Concejo Municipal. El error indicado no tendría mayores consecuencias, si la exclusión del Concejo no privara al Juez de "investidura regular". La ausencia de investidura regular tiene la consecuencia de que el designado no pase de ser un mero seudomagistrado, circunstancia que, por mandato expreso de la Constitución Política, priva, ineludiblemente, de validez a todas sus resoluciones (art. $7^{\circ}$ C.P.), además de comprometer la responsabilidad extracontractual del Municipio, junto con la del seudomagistrado y de perjudicar a terceras personas. 
La designación en el cargo de Juez de Policía Local debe, necesariamente, cumplir con dos tipos de requisitos esenciales: el primero de ellos se refiere a los requisitos de "fondo" y, el segundo es de "procedimiento". Tanto un vicio de fondo como uno de procedimiento excluyen la existencia de "investidura regular". Cualquiera de ambos tipos de vicios son causal de nulidad del acto, aunque la Contraloría General de la República hubiera tomado razón del acto de nombramiento.

La ley orgánica constitucional de Municipalidades № 18.695 omite indicar, expresamente, la necesidad del acuerdo del Concejo para la designación de Juez de Policía Local.

La solución del problema indicado exige una interpretación jurídica armónica, integral y finalista del ordenamiento jurídico, a partir de los principios de derecho constitucionales y de su aplicación al ordenamiento legal, en aplicación de los principios de preeminencia y de obligatoriedad de las normas de la Constitución, para así cumplir con el principio de juridicidad, del respeto de la libertad y de los derechos públicos subjetivos.

\section{EL REQUISITO DE LA INVESTIDURA REGULAR}

En un régimen jurídico-político propio de una república democrática, como acontece en Chile (art. $4^{\circ}$ C.P.), los órganos del Estado deben someterse al ordenamiento jurídico, sin excepción. Entre los elementos constitutivos de un órgano público: gubernamental, administrativo, judicial o legislativo están los funcionarios, personas naturales que desempeñan cargos públicos. Los funcionarios o autoridades que sirven cargos públicos, sean de elección popular o de nombramiento por los órganos facultados para ello, deben ser investidos en sus cargos con plena sujeción al procedimiento jurídico vigente, lo que constituye un requisito indispensable para la existencia de un Estado de Derecho.

El requisito de la investidura regular rige respecto de todos los cargos públicos, sin excepción. Lo indicado tiene su fundamento principal en los principios jurídicos de "preeminencia" y de "obligatoriedad" de la Constitución Política. La Carta Fundamental en el inciso primero del artículo $6^{\circ}$, dice: "Los órganos del Estado deben someter su acción a la Constitución y a las normas dictadas conforme a ella". El citado precepto tiene aplicación integral, en consecuencia él rige el ejercicio de las potestades constituyentes, legislativa —en todo el ámbito de normas con rango de ley-, de gobierno, de administración y jurisdiccionales. Las normas de preeminencia y de investidu- 
ra regular son, como se dijo, de general aplicación, al punto de regir hasta la designacion del cargo de Presidente de la República, los cargos de parlamentarios, de miembros del Poder Judicial, del Tribunal Constitucional, de Comandantes en Jefe de las Instituciones de las Fuerzas Armadas, de Contralor General de la República, entre otros. Por el hecho de ser Chile una república democrática, resulta que nadie es dueño de los cargos públicos, sino que quienes los ocupan son meros servidores públicos, personas que están integralmente sometidas a los principios de juridicidad y de responsabilidad. Lo expresado revela que nadie es dueño del cargo por tiempo indefinido, durante toda su existencia; el cargo público no puede formar parte del patrimonio hereditario dejado por el causante, luego de su muerte.

El inciso $1^{\circ}$ del artículo $7^{\circ}$ de la C.P., dice: "Los órganos del Estado actúan válidamente previa investidura regular de sus integrantes...”. De esta disposición surgen dos importantes consecuencias jurídicas; la primera de ellas ratifica lo que hemos sostenido, en el sentido de que la norma indicada rige a todos los cargos públicos, y no solamente a quienes desempeñan funciones de gobierno o administrativas. La segunda consecuencia de la norma indicada expresa, que la investidura debe ser "regular", esto es, conforme a derecho, es decir, que la investidura debe estar en plena armonía con el

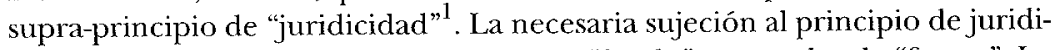
cidad comprende tanto a los requisitos de "fondo" como a los de "forma". La sujeción o respeto de los requisitos de forma, más correctamente a los requisitos de "procedimiento", significa derechamente que no basta o que no es suficiente con que la persona que es investida haya dado sólo cumplimiento a los requisitos de fondo, prescritos en el ordenamiento jurídico. Como sería reunir sólo los requisitos de nacionalidad, edad, de estudios o de título, de ideoneidad moral, de salud compatible y de cumplimiento a las leyes militares. Sin perjuicio de los antecedentes indicados - de fondo-, para la validez de la investidura es básico que la designación, además, se haya sujetado a las normas de procedimiento establecidas y vigentes para la instalación en el cargo. La falta de alguno de los requisitos de fondo o de procedimiento tienen como efecto la nulidad de la designación o del nombramiento, lo que excluye la existencia de investidura regular. A título de ejemplo, nos referiremos a los requisitos de fondo contenidos en el inciso $1^{\circ}$ del artículo 25 de la C.P., que dice: "Para ser elegido Presidente de la República se requiere haber nacido en el territorio de Chile, tener cumplidos cuarenta

${ }^{1}$ Ver nuestro Juridicidad, Legitimidad y Principios Generales de Derecho, en esta Revista, $\mathrm{N}^{\mathrm{os}} 51 / 52,1992,127-144$. 
años de edad y poseer las demás calidades necesarias para ser ciudadano con derecho a sufragio". El artículo 13 de la C.P. establece los requisitos de la ciudadanía.

En los artículos 26, 27 y 29 de la C.P. se contienen las normas básicas de procedimiento para poder ser regularmente investido en el cargo de Presidente de la República. Enseguida, reproduciremos parcialmente las disposiciones esenciales de los artículos indicados:

“Art. 26. inciso $1^{\circ}$....la elección —de Presidente-se realizará, en la forma que determine la ley, noventa días antes de aquel en que deba cesar en el cargo el que esté en funciones". "Art. 27. inciso 1‥ EI proceso de calificación de la elección presidencial deberá quedar concluido dentro de los cuarenta días siguientes a la primera elección o de los veinticinco días siguientes de la segunda"; inciso 3‥ El Congreso Pleno, reunido en sesión pública noventa días después de la primera o única elección y con los miembros que asistan, tomará conocimiento de la resolución en virtud de la cual el Tribunal Calificador proclama al Presidente electo"; "inciso $4^{\circ}$. En este mismo acto, el Presidente electo prestará ante el Presidente del Senado, juramento o promesa de desempeñar fielmente el cargo de Presidente de la República, conservar la independencia de la Nación, guardar y hacer guardar la Constitución y las leyes, y de inmediato asumirá sus funciones".

"Art. 29. inciso $3^{2}$. Si la vacancia - del cargo de Presidentese produjere faltando menos de dos años para la próxima elección general de parlamentarios, el Presidente será elegido por el Congreso Pleno por la mayoría absoluta de los senadores y diputados en ejercicio y durará en el cargo hasta noventa días después de la elección general"; "inciso 4º. Si la vacancia se produjere faltando dos años o más para la próxima elección general de parlamentarios, el Vicepresidente, dentro de los diez primeros días de su mandato, convocará a los ciudadanos a elección presidencial para el nonagésimo día después de la convocatoria”.

Sobre la base de una interpretación gramatical y finalista del Derecho Público, y atendiendo a lo establecido en los artículos $4^{\circ}, 7^{\circ}, 27$ y 29 de la C.P., resulta que por ser Chile una república democrática, y por la aplicación de los principios de "preeminencia" y de "obligatoriedad" de las disposiciones constitucionales, y de los requisitos de validez de los actos públicos (sea que se trate de actos de gobierno, de administración o judiciales) tenemos que la "investidura regular", en ambos efectos: de fondo y de procedimiento, constituye uno de los requisitos esenciales para el ejercicio válido de las potestades públicas. El cumplimiento previo del requisito de la "investidura regular", para ocupar válidamente un cargo público, no admite excep- 
ciones en un régimen jurídico-político de Estado de Derecho ${ }^{2}$. Lo indicado ha quedado de manifiesto con la simple lectura de las normas constitucionales que rigen la investidura regular del Presidente de la República.

\section{EFECTOS JURIDICOS \\ DE IAA FALTA DE "INVESTIDURA REGULAR"}

La exteriorización o dinamización de una potestad - o competencia- requiere como condición esencial de validez de la concurrencia de elementos o factores básicos o medulares. En primer término es necesario que el ordenamiento jurídico contemple la existencia —o la creación antelada- de un cargo público. Enseguida hay que considerar los términos de la competencia -o atribuciones - otorgadas de manera previa y explícita a dicho cargo. Luego es imprescindible que el cargo sea ejercido por un funcionario o autoridad pública -que el cargo no se encuentre vacante-. Que la designación por nombramiento o elección popular, según corresponda, de la persona que ejercerá las atribuciones ligadas al cargo, haya sido investida en el empleo en forma "regular", con plena sujeción a los requisitos de "fondo" y de "procedimiento" que estén vigentes en el momento de la asunción del cargo. Que para la puesta en movimiento de las funciones - competenciase den los motivos que autorizan la dictación del acto. Los motivos consisten en la existencia previa y real de las circunstancias de hecho y de derecho descritas en la competencia, de manera integral cuando se trata de potestades ligadas o vinculadas a la ley ${ }^{3}$; si la potestad fuere discrecional la descripción de los motivos es más difusa o parcial, dejando un espacio a la apreciación de los motivos entregada al funcionario o autoridad que ocupa el cargo ${ }^{4}$, todo ello sujeto al principio de juridicidad ${ }^{5}$.

Una vez cumplidos los requisitos indicados, hay que atender al "objeto" del acto, es decir, al contenido directo e inmediato perseguido con la dictación del acto. El objeto del acto, por ejemplo la designación de un funcionario, debe estar en armonía con la potestad que se invoca o dinamiza.

${ }^{2}$ Ver inciso $2^{\circ}$ del art. $6^{\circ}$ y art. $7^{\circ}$, ambos de la Constitución.

"Ver nuestro Manual de Derecho Administrativo, Ed. Jca. de Chile, 1979.

4Ver nuestro Limites Constitucionales de la Discrecionalidad Administrativa, "Revista Chilena de Derecho", vol. 16.

${ }^{5}$ Ver nuestro Función Pública y Carrera Funcionaria, en esta Revista, № 50 (1991), 197-222. 
Enseguida, es necesario atender al fin perseguido por el acto; el fin es el "objetivo finalista" - no el inmediato-, para el que, en definitiva, se otorgó la competencia que se está ejerciendo. El fin es la meta que impone la orientacion juridica hacia la cual debe encaminarse el acto, en el ejercicio jurídico de la competencia del órgano. Un acto que pretendiere ser emitido hacia la consecución del fin de bien común específico que le indica la competencia del órgano, pero que, en la realidad, el fin verdadero fuere distinto de aquél, estaría viciado de nulidad; en ese caso se habría producido la desviación del fin autorizado en la competencia. Un acto orientado hacia un fin de bien común específico distinto del invocado, y que ha sido autorizado en la competencia, sirviéndose de una suerte de camuflaje, de una antijuridicidad encubierta, causaría la nulidad del acto, por falta de validez del mismo, entre otras razones por la vulneración del articulo $7^{\circ}$ de la C.P.

La desviación del fin del acto no constituye, exclusivamente, un vicio de ilegalidad, puesto que aquélla, en último término, consiste en una violación de la Constitución Política ${ }^{6}$.

Todos los requisitos anteriormente indicados tienen, necesariamente, para la validez del acto, que haber dado estricto cumplimiento a los requisitos de "fondo" y al procedimiento constitucional, legal o reglamentario vigente $^{7}$. El acto que es emitido sin respetar el procedimiento que le es aplicable, no constituye una actuación válida, debido a que aquél adolece de nulidad absoluta.

Si se hubieren cumplido tanto los requisitos de fondo como los de procedimiento, pero la autoridad o autoridades que emitieron el acto adolecieran, total o parcialmente, de falta de investidura regular, la actuación estaría, de todas maneras, viciada de antijuridicidad y, en consecuencia, el acto sería nulo.

La falta de investidura regular hace que el presunto funcionario sea, en realidad, sólo un seudofuncionario. Todos los actos emitidos por un seudofuncionario invalidan los actos o resoluciones en que éste hubiera intervenido, por vulneración de la norma establecida en el artículo $7^{\circ}$ de la C.P.

${ }^{6}$ Ver nuestro Fuerza Normativa de las Disposiciones Contenidas en el Capitulo I "Bases de la Institucionalidad", de la Constitución Politica de 1980, "Rev. de Derecho y Jurisprudencia", tomo LXXXVII, № 1, 1990.

${ }^{7}$ Ver nuestro El Acto Administrativo (Legalidad, Efectos e Impugnación), Ed. Jca. de Chile, 1981, 90-94. 
Los actos o resoluciones —administrativas, de gobierno o judiciales - emitidos por un seudofuncionario, facultan jurídicamente a todas las personas a quienes hubieran estado dirigidos los efectos del acto, a solicitar ante los Tribunales su declaración de nulidad. Lo anterior es sin perjuicio de la facultad o del derecho de quienes se sintieren lesionados en sus derechos públicos subjetivos, a demandar el pago de las indemnizaciones por los daños sufridos. Las indemnizaciones afectan jurídicamente al Fisco o al órgano personalizado y, también, al seudofuncionario causante del daño. El derecho a la indemnizacion emana de la C.P. y de la LOCBGAE 8

\section{NORMAS JURIDICAS QUE RIGEN EL NOMBRAMIENTO DE JUEZ DE POLICIA LOCAL}

En ejercicio de las facultades otorgadas por el decreto ley № 2.042, de 1977, se fijó el texto refundido, coordinado y sistematizado de la ley $\mathrm{N}^{2} 15.231$, sobre "Organización y Atribuciones de los Juzgados de Policía Local". El fundamento de esta medida se debió a razones de orden administrativo y de utilidad práctica, orientadas a señalar detenidamente las fuentes legales que originaron las modificaciones experimentadas por los distintos preceptos del texto refundido. El artículo $1^{\circ}$ del D.S. No 307 , del Ministerio de Justicia (D.O. del 23.05.78), que refundió la Ley № 15.231, establece que tanto la organización como las atribuciones de los Juzgados de Policía Local, se regirán por su texto. El indicado D.S. 307, en su artículo $2^{\circ}$ establece una diferencia en cuanto a los órganos que, en uno y otro caso, estarán facultados para desempeñar las funciones de Juez de Policía Local. En el primer caso se refiere a las ciudades cabeceras de provincias y a las comunas de la provincia de Santiago, cuyas comunas tengan una entrada anual superior a treinta sueldos vitales anuales. En estos casos se indica que las materias contenidas en el texto refundido serán ejercidas por funcionarios que se denominarán Jueces de Policía Local. Cuando se trate de comunas que tengan un ingreso inferior al indicado, previa ratificación de la Asamblea Provincial podrá designarse Juez de Policía Local. En circunstancias distintas a las precedentes los Alcaldes desempeñarán las funciones de Juez de Policía Local. Enseguida el texto refundido exige que para ser designado Juez de Policía Local el interesado

${ }^{8}$ Ver nuestro La Responsabilidad Extracontractual del Estado en la Constitución Politica de 1980, Ed. Jurídica de Chile, 1982. 
debe reunir las calidades y requisitos para ser Juez de Letras de mayor cuantía de simple departamento. De más está indicar que las Asambleas Provinciales contempladas en la Constitución Política de 1925, que a la fecha del texto refundido estaba vigente, nunca fueron creadas, ellas integraron el grupo de normas constitucionales a las que se designó como "programáticas".

\subsection{Organos que deben intervenir en la designación de Juez de Policia Local}

La designación de Juez de Policía Local es una atribución municipal, que debe someterse a un procedimiento relativamente complejo, en el que existen actos trámites que deben orientarse al acto administrativo terminal, que consiste en la designación del Juez de Policía Local y a la investidura regular de éste. En primer término es necesario que exista la vacante correspondiente, dada esta circunstancia, la Corte de Apelaciones respectiva procede a abrir el concurso pertinente, dentro de un plazo de diez días. Para participar en el indicado concurso existe una preferencia legal ${ }^{9}$, que nos parece contraria a disposiciones constitucionales, por ejemplo a la del № 17 del artículo 19 de la Constitución Política, que dice:

"Art. 19. La Constitución asegura a todas las personas: $17^{\circ} \mathrm{La}$ admisión a todas las funciones y empleos públicos, sin otros requisitos que los que impongan la Constitución y las leyes". Si alguien llegare a pensar que no existe vicio de inconstitucionalidad, debido a que en la última frase del № 17 dice "y las leyes", sería suficiente para sacarlo de su error con tener en cuenta el texto del № 26 del artículo 19 de la Constitución, que dice: "La Constitución asegura a todas las personas: $N$ o 26. La seguridad de que los preceptos legales que por mandato de la Constitución regulen o complementen las garantías que ésta establece o que las limiten en los casos en que ella lo autoriza, no podrán afectar los derechos en su esencia, ni imponer condiciones, tributos o requisitos que impidan su libre ejercicio". Nuestra crítica se refiere al inciso $2^{\circ}$ del artículo $4^{\circ}$ del texto refundido, que dice: "La Corte deberá formar la terna correspondiente de entre los funcionarios de las Municipalidades de la provincia, de acuerdo con las disposiciones de la Ley $\mathrm{N}^{\circ}$ 11.469. Para este efecto, los secretarios municipales deberán remitir a las Cortes respectivas, dentro del mes de enero de cada año, una nómina completa de los empleados que puedan ser considerados en las ternas". Salvo que no se presentaren candidatos de origen municipal, al

Ver el inciso $2^{\mathrm{O}}$ del art. $4^{2}$ del OS. № 307 , Ministerio de Justicia, esta norma es contraria al principio constitucional de "igualdad ante el Derecho", principio que la C.P., en su art. 19 № 2, erróneamente califica de "igualdad ante la ley". 
respectivo concurso, la Corte podrá formar la terna discrecionalmente; sin embargo, la Corte "deberá preferir a los jueces de policía local o abogados municipales de la República que se presenten"10.

Propuesta la terna presentada por la Corte, la designación de Juez de Policía Local corresponde hacerla a la Municipalidad. Este órgano administrativo deberá efectuar el nombramiento dentro del término de treinta días de recibida la terna.

Como ha quedado claramente establecido, en la designación de Juez de Policía Local intervienen dos órganos: uno del Poder Judicial, representado por la respectiva Corte de Apelaciones, y el otro por un órgano de la administración comunal: el Municipio, todo ello de acuerdo con un procedimiento consistente en un concurso de postulantes, de los cuales la Corte formará una terna, la que será remitida a la Municipalidad ${ }^{11}$.

\subsubsection{Organos Municipales "esenciales" que deben intervenir en la designación de Juez de Policía Local}

El artículo $4^{\circ}$ del texto refundido, textualmente, dice, en su primera parte, que: "Los jueces de policía local serán designados por la Municipalidad que corresponda". Esta norma exige determinar, con exactitud, qué órganos constituyen una municipalidad, entendiendo que nos referimos a los órganos superiores de aquélla. Para dilucidar este problema es necesario atenerse a la actual Ley Orgánica Constitucional de Municipalidades № 18.695 y, como es lógico, en primer lugar a la Constitución Política. En el Capítulo XIII GOBIERNO YADMINISTRACION DEL ESTADO, en el párrafo "Administración Comunal", el inciso $1^{\circ}$ del artículo 107, dice en su primera parte: "La administración local de cada comuna o agrupacion de comunas que determine la ley reside en una municipalidad, la que estará constituida por el alcalde, que es su máxima autoridad, y por el concejo...”. El inciso $3^{\circ}$ del mismo artículo, en su primera parte, expresa: "Una ley orgánica constitucional determinará las funciones y atribuciones de las municipalidades. Dicha ley señalará, además, las materias de administración municipal que el alcalde, con acuerdo del concejo...". Enseguida el artículo 108, en su inciso primero establece: "En cada municipalidad habrá un concejo integrado por concejales elegidos por sufra-

${ }^{10}$ Ver Eduardo Soto Kloss, Estado de Derecho y procedimiento administrativo, Revista $\mathrm{N}^{2} 28$ (1980), 101-124.

${ }^{11}$ Ver Manuei Daniel A., La organización administrativa en Chile. Bases Fundamentales ( $2^{\mathrm{a}}$ ed.). Ed. Jca. de Chile, 1985, 145 ss. 
gio universal en conformidad a la ley orgánica constitucional de municipalidades...". Inmediatamente, el inciso $2^{\circ}$, dice: "El concejo será un órgano encargado de hacer efectiva la participación de la comunidad local, ejercerá funciones normativas, resolutivas y fiscalizadoras y otras atribuciones que se le encomienden, en la forma que determine la ley orgánica constitucional respectiva".

El inciso final del indicado artículo, realza la importancia del concejo, como órgano superior o esencial de la organización municipal, al decir: "La ley orgánica de municipalidades determinará las normas sobre organización y funcionamiento del concejo y las materias en que la consulta del alcalde al concejo será obligatoria y aquéllas en que necesariamente se requerirá el acuerdo de éste. En todo caso, será necesario dicho acuerdo para la aprobación del plan comunal de desarrollo, del presupuesto municipal y de los proyectos de inversión respectivos".

Como puede comprobarse, las municipalidades, que según la Constitución Política, "son corporaciones autónomas de derecho público, con personalidad jurídica y patrimonio propio", están estructuradas sobre la base de dos órganos superiores: el alcalde y el concejo. La propia Constitución, a título de ejemplo, señala que habrán materias en las que la consulta del alcalde al concejo "será obligatoria", y otras en que el acuerdo del concejo "será imprescindible". Entre las últimas, esto es, en las que el acuerdo del concejo es esencial, también, a título de ejemplo, la Constitución indica, comenzando por utilizar la frase "en todo caso" a tres materias que están directamente ligadas a los fines para los que han sido creados los municipios. La segunda parte del inciso $2^{\circ}$ del artículo 107 de la Carta, refiriéndose a las Municipalidades, dice: "cuya finalidad es satisfacer las necesidades de la comunidad local y asegurar su participación en el progreso económico, social y cultural de la comuna".

Por consiguiente, cuando en la primera parte del inciso $1^{\circ}$ del artículo $4^{\circ}$ del texto refundido sobre "Organización y Atribuciones de los Juzgados de Policía Local", se dice, textualmente, que: "Los jueces de policía local serán designados por la Municipalidad que corresponda", no existe razón jurídica alguna para excluir de la participación en dicha designación a alguno de los dos órganos superiores de la municipalidad, esto es, no excluir al alcalde ni al concejo. Lo expresado se basa en el tenor literal de la Constitución Política, cuyo artículo $6^{\circ}$, expresa:

"Art. 6 Los órganos del Estado deben someter su acción a la Constitución y a las normas dictadas conforme a ella. inciso $2^{\circ}$ Los preceptos de esta Constitución obligan tanto a los titulares o integrantes de dichos 
órganos como a toda persona, institución o grupo. inciso $3^{\circ} \mathrm{La}$ infracción de esta norma generará las responsabilidades y sanciones que determine la ley" ${ }^{2}$.

En el primer inciso del artículo transcrito se establece el principio constitucional de preeminencia de la Constitución". En el segundo, no siendo ello imprescindible, salvo para prevenir los efectos "del peso de la noche en materia jurídica", se indica que el principio aludido obliga a todos sin excepción, comenzando por los órganos públicos, entre los que se cuentan las municipalidades que están constituidas por el Alcalde y el Concejo y el inciso final establece como sanción la nulidad, que ciertamente es de derecho público, y las responsabilidades consiguientes.

\subsubsection{Atribuciones genéricas que la Constitución Politica otorga al Concejo}

Retomando lo expresado, de modo genérico, en el inciso $2^{\underline{\alpha}}$ del artículo 108 de la C.P., donde se dice que el concejo ejercerá funciones normativas, resolutivas y fiscalizadoras, además de otras atribuciones que se le encomienden, en la forma que determine "la ley orgánica constitucional respectiva", queda en evidencia la trascendental importancia del concejo, en cuanto órgano colegiado y de elección popular. La importancia a que hemos hecho referencia queda en evidencia sólo con considerar la naturaleza de las potestades que la propia Constitución le otorga, la función "normativa", constituye la atribución para emitir normas jurídicas obligatorias, generales, abstractas —en cuanto no se refieren exclusivamente a un caso particular y concreto específico-, de duración ilimitada, salvo que interviniera su revocación o nulidad declarada judicialmente. El otorgamiento constitucional de una potestad normativa equivale al reconocimiento de que el concejo dispone de una potestad reglamentaria, cuyas características se asemejan a la potestad legislativa, contenida en el artículo 60 de la C.P. y, también, a los tres tipos o clases de potestades reglamentarias del Presidente de la República. En cuanto al otorgamiento de la potestad resolutiva, que consiste en adoptar resoluciones o determinaciones sobre materias genéricas, comprendidas dentro de los diversos fines propios del municipio, es también un factor que viene a destacar la

${ }^{12}$ En cuanto a las responsabilidades, tratándose de la extracontractual, aunque no se hubiera dictado la ley, a que alude esta norma, siempre habrá derecho a reclamar la indemnización por el daño causado, aquélla recaerá sobre el Fisco o sobre el órgano personificado. Este principio rige por igual, sea que el daño provenga de una acción o de una omisión. La relación entre la causa del daño y el perjuicio reclamado debe ser directa. Ver el inciso $2^{\prime \prime}$ del art. 38 de la C.P. 
importancia del concejo. La Constitución, como ya indicáramos, señaló solamente a título de ejemplo, en el inciso final del artículo 108, que será necesario el acuerdo del concejo "para la aprobación del plan comunal de desarrollo, del presupuesto municipal y de los proyectos de inversión respectivos".

Finalmente, en lo que atañe al otorgamiento constitucional al concejo de funciones "fiscalizadoras", refuerza nuestra tesis de la importancia que la "ley de leyes", vale decir, la Constitución reconoce al control jurídico sobre los actos u omisiones de los órganos públicos, debido a que uno de los elementos básicos del Estado de Derecho es, precisamente, el control jurídico del ejercicio del poder público ${ }^{18}$.

Por consiguiente, desde el punto de vista jurídico-administrativo, cuando una norma legal, como es el caso del D.S. № 307, del Ministerio de Justicia, dice que: "Los jueces de policía local serán designados por la Municipalidad que corresponda...", es absurdo y sin fundamento interpretar que el órgano Municipal es equivalente al cargo de Alcalde, como también lo sería el sostener que dicho órgano - la municipalidad-consiste en el Concejo Comunal, con exclusión del Alcalde. Jurídicamente una municipalidad está estructurada por dos órganos superiores: el Alcalde y el Concejo Comunal. La interpretación indicada, relativa a los órganos que configuran, esencialmente, una municipalidad es algo que está fuera de toda duda, debido a que la ley orgánica constitucional de Municipalidades, ateniéndose estrictamente al texto constitucional, en su artículo $2^{\circ}$, dice textualmente: "Las municipalidades estarán constituidas por el alcalde, que será su máxima autoridad, y por el concejo. Cada municipalidad contará, además, con un consejo económico y social comunal de carácter consultivo". El inciso $1^{\circ}$ del artículo 12 de la LOC de Municipalidades, dice: "Las funciones y atribuciones de las municipalidades serán ejercidas por el alcalde y por el concejo en los términos que esta ley señala". La disposición transcrita tiene un sentido genérico y amplio, puesto que ella se refiere "a las funciones y atribuciones de las municipalidades", el amplio sentido de la norma comprende, necesariamente, a todas las funciones y atribuciones de las municipalidades, especialmente, a las más importantes, entre las que está el nombramiento de los jueces de policía local. El artículo 53 de la LOC de Municipalidades, que se refiere a las "atribuciones del alcalde", en la letra c) dice expresamente: "Nombrar y

${ }^{13}$ Sin control jurídico y, también, económico la sujeción de los órganos del Estado al principio de juridicidad sería un mero espejismo; tampoco estarían garantizados el respeto de la libertad y de los derechos públicos subjetivos. 
remover a los funcionarios de su dependencia de acuerdo con las normas estatutarias que los rijan". En relación con la norma transcrita es necesario señalar que los funcionarios municipales gozan de la estabilidad en el empleo, como lo indica el inciso $1^{0}$ del artículo 35 de la LOC de Municipalidades, que dice: "El personal gozará de estabilidad en el empleo y sólo podrá cesar en él por renuncia voluntaria debidamente aceptada; por jubilación, o por otra causal legal basada en su desempeño deficiente, en el incumplimiento de sus obligaciones, en la pérdida de requisitos para ejercer la función, en el término del período legal o en la supresión del empleo. Lo anterior es sin perjuicio de lo establecido en el artículo 38". Es necesario hacer presente que las facultades de nombrar y de remover a los funcionarios de su dependencia, que el artículo 53 letra c) confiere al alcalde, está limitada por el principiọ de la carrera funcionaria. Dicho principio está comprendido en la Constitución Política y en la LOC de Bases Generales de la Administración del Estado ${ }^{14}$.

Entre las atribuciones privativas del alcalde se encuentra la designación de los funcionarios de su dependencia, de este género de atribuciones están exentos los jueces de policía local. El inciso $1^{\circ}$ del artículo $8^{\circ}$ del D.S. 307, dice: "Los jueces de policía local serán independientes de toda autoridad municipal en el desempeño de sus funciones. Son aplicables a los jueces de policía local las disposiciones de los artículos 84,85 y 86 de la Constitución Política; durarán, por consiguiente, indefinidamente en sus cargos y no podrán ser removidos ni separados por la Municipalidad". La parte final del inciso transcrito indica que ni el alcalde ni el concejo pueden remover al juez de policía local, aun cuando actúen de acuerdo en dicho objetivo. El inciso $2^{\circ}$ del indicado artículo; textualmente, dice: "Los jueces de policía local estarán directamente sujetos a la supervigilancia directiva, correccional y cconómica de la respectiva Corte de Apelaciones". La municipalidad debe informar, anualmente, a la Corte de Apelaciones un informe sobre la apreciación que le merezca el juez de policia local, "atendida su eficiencia, celo y moralidad en el desempeño de su cargo".

La calificación anual de los jueces de policía local corresponde a la respectiva Corte de Apelaciones, integrada con el respectivo Presidente del Colegio de Abogados, teniendo en consideración el informe de la municipalidad correspondiente. El informe anual a que hemos hecho referencia, que debe enviarse por la municipalidad a la Corte de Apelaciones antes del

${ }^{14} \mathrm{La}$ función judicial debe ser libre, ajustada a derecho e imparcial, por estos motivos para su eficiencia y eficacia no puede depender de una autoridad de la Administración del Estado. Ver art. $8^{\circ}$ del D.S. № 307. 
15 de diciembre, también debe adoptarse con el acuerdo del Alcalde y del Concejo.

Si un juez de policía local se sintiera perjudicado con la calificación de la Corte de Apelaciones, puede apelar de la resolución ante la Corte Suprema, dentro del plazo de cinco días hábiles. La remoción de los jueces de policía local corresponde a la Corte Suprema, ese acuerdo relativo a la remoción del juez de policía local, acordado por la Corte Suprema, por "declaración de su mal comportamiento", "se comunicará al alcalde de la respectiva municipalidad para su cumplimiento".

La independencia del juez de policía local respecto del municipio, y el procedimiento para su nombramiento, está en armonía con lo establecido en el artículo $7^{\circ}$ del D.S. 307, que expresa: "Los jueces de policía local prestarán ante el alcalde el juramento prevenido por el artículo $304 \mathrm{del}$ Código Orgánico de Tribunales".

Demostraremos que no solamente la designacion de juez de policía local debe efectuarse, de acuerdo con el principio de juridicidad por el alcalde con acuerdo del concejo, sino que, también, debe sujetarse al mismo procedimiento la designación de secretario de estos tribunales. Esto se deduce de la interpretación literal y finalista del inciso primero del artículo $6^{\circ}$ del D.S. 307, que dice: "En caso de impedimento o inhabilidad del juez de policía local será subrogado por el secretario del mismo tribunal, siempre que sea abogado". El subrogante debe, necesariamente, tener la misma independencia de la municipalidad que la del juez subrogado, de no ser así el juez subrogante actuaría como dependiente del municipio, lo que contravendría lo dispuesto en el inciso primero del artículo $8^{\circ}$ del indicado D.S. 307.

\section{JURISPRUDENCIA DE TRIBUNALES SUPERIORES DE JUSTICIA}

La Corte Suprema confirmó la sentencia apelada, de la Corte de Apelaciones de Puerto Montt, dictada en recurso de protección interpuesto por el recurrente don H.M. Pérez Sánchez en contra del Decreto № 805, del 20.12.1993 emitido por el alcalde don R. Blanco Watson. En el considerando cuarto de la I. CAP., se dice: "Que el recurrido — el alcalde- argumenta que tiene la facultad de designar al Juez del Segundo Juzgado de Policia Local, en virtud de las atribuciones que le confiere el artículo 56 de la Ley Orgánica Constitucional $\mathrm{N}^{\circ} 18.695$; entre otras: a) representar judicial y extrajudicialmente a la Municipalidad; c) nombrar y remover a los funcionarios de su dependencia 
de acuerdo con las normas estatutarias que los rijan. El hecho de representar judicial y extrajudicialmente a la Municipalidad, no guarda ninguna relación con la facultad que dice tener el recurrido en relación a la designación de Juez de Policía Local, razón por la cual la desestimamos de plano". En el considerando quinto, párrafos $2^{\circ}$ y $3^{\circ}$, se dice: "El artículo $8^{\circ}$ de la Ley 15.231 prescribe que los Jueces de Policía Local serán independientes de toda otra autoridad municipal, en el desempeño de sus funciones. Son aplicables a los Jueces de Policía Local las disposiciones de los artículos 84, 85 y 86 de la Constitución Política; durarán por consiguiente, indefinidamente en sus cargos y no podrán ser removidos por la Municipalidad"; "Los Jueces de Policía Local estarán directamente sujetos a la supervigilancia directiva, correccional y económica de la respectiva Corte de Apelaciones".

En el inciso final del indicado inciso quinto, se dice: "Del análisis de la disposición transcrita, se desprende fehacientemente que los Jueces de Policía Local no pueden estar incluidos entre los funcionarios de la dependencia del Alcalde, que menciona la letra c) del artículo 53 de la Ley Orgánica Constitucional № 18.695 y por consiguiente, no lo faculta ley alguna para nombrarlos o removerlos en forma unipersonal como a los demás funcionarios municipales, a quienes se les aplican las disposiciones del título II "Carrera Funcionaria" de la Ley № 18.883, que se refieren al ingreso, capacitación y promociones de los mismos, como también el título III de la Ley mencionada "De las obligaciones funcionarias", que reglamentan la jornada de trabajo, subrogación y responsabilidad administrativa, normas que se aplican a quienes dependen del Alcalde". En el considerando sexto, se dice: "En el considerando tercero dijimos que la Municipalidad es una Corporación de derecho público compuesta por el Alcalde y el Concejo; luego si la ley especifica que tal o cual atribución pertenece a la Municipalidad, mal puede afirmarse que ella le corresponde al Alcalde, sosteniendo que ambos términos son sinónimos". El párrafo segundo del considerando séptimo, se dice: "En parte alguna esta ley - 18.695 - atribuye la designación de Juez de Policía Local al Alcalde y dentro de su contexto, si bien el artículo 55 no incluye este acto entre las materias en que se requerirá el acuerdo del Concejo con posterioridad al fijar en el artículo 66, las atribuciones de este cuerpo colegiado, letras a) a la k), prescribe en el inciso final "lo anterior es sin perjuicio de las demás atribuciones y funciones que le otorga la ley", que en el presente caso no son otras que las señaladas en el referido artículo $4^{\circ}$ de la Ley $N^{\circ} 15.231$, que hemos descrito en la reflexión anterior en que sí se menciona en forma expresa que tal designación corresponde a la Municipalidad, que está integrada como dijimos por el Alcalde y el Concejo". El párrafo primero del conside- 
rando noveno expresa: "Que del mismo modo, carece de toda trascendencia respecto de lo planteado en autos, la Ley $N^{\circ} 19.236$ que crea un Juzgado de Policía Local en Puerto Montt y que modifica la planta del personal, porque nadic desconoce que los Jueces de Policía Local integran la referida planta, pero ello no acredita, como se ha repetido, que sean funcionarios de la dependencia del Alcalde". En el considerando undécimo, se dice: "Que concordante con lo antes expuesto, a juicio de estos sentenciadores, la actitud del alcalde de la Municipalidad de Puerto Montt, de designar Juez del Segundo Juzgado de Policía Local sin requerir el acuerdo del Concejo Municipal, sí importa una vulneración al principio de legalidad que consagra nuestra Carta Fundamental en el № $2^{\circ}$ del artículo 19 que dice: "ni la ley ni autoridad alguna podrán establecer diferencias arbitrarias" y que el artículo 20 del mismo texto constitucional otorga acción a quien sufre privación, perturbación o amenaza en el legítimo ejercicio de su derecho para que recurra a la Corte de Apelaciones respectiva, a fin de que este tribunal adopte las providencias que juzgue necesarias para establecer el imperio del derecho y asegurar la debida protección al afectado, sin perjuicio de los derechos que pueda hacer valer ante los tribunales correspondientes, motivo por el cual se desestima la alegación de la recurrida - el Alcalde - en cuanto a la no procedencia del mencionado recurso para impugnar la validez del Decreto Afecto № 805, por tener también la vía legal que señala el artículo 122 de la Ley № 18.695 en actual vigencia". Finalmente, en el párrafo $2^{\circ}$ del considerando decimotercero, se dice: "Por estas consideraciones apreciadas en conciencia, lo dispuesto en los artículos 19 № 2 y 20 de la Constitución Política de la Republica y disposiciones constitucionales y legales y textos citados, Auto Acordado de la Excma. Corte Suprema sobre Tramitación y Fallo del Recurso de Protección, se acoge el interpuesto a fojas 2 por M. Pérez Sánchez sólo respecto de la garantía a que se refiere la disposición constitucional mencionada, y se declara que se invalida el Decreto Afecto № 805, de fecha 20.12.1993, por no haberse convocado al Concejo de la I. Municipalidad de Puerto Montt para que concurra a la designación del cargo de Juez del Segundo Juzgado de Policía Local de esta ciudad".

\subsection{Problema suscitado en relación con Recurso de Protección ante la I. CAP de Iquique}

En el fallo emitido por la I. CAP de Puerto Montt y ratificado por la Excma. Corte Suprema, en el considerando décimo, se expresa: "Que tanto el recurrente M. Pérez Sánchez, como el recurrido y el tercero coadyuvante H. Ocampo P. 
han hecho referencia en apoyo de sus respectivos planteamientos, a un fallo judicial dictado por la Corte de Apelaciones de Iquique, que fuera confirmado por sentencia de fecha 23.12.1993 por la Excma. Corte Suprema, mediante el cual un abogado interpuso un recurso de protección, a fin de que se respetara la decisión del Concejo Municipal en la designación del cargo de Juez del Segundo Juzgado de Policía Local de la ciudad de Iquique, creado por la Ley № 19.236 y que fuera convocado - el Concejo- a iniciativa del propio Alcalde y que éste después desconoció nombrando a otro integrante de la terna", enseguida, agrega: "Estimamos que en el fondo del problema resuelto por estos Tribunales consistió en determinar si el Concejo tiene o no la atribución para la cual fue convocado, existiendo en el presente caso, a nuestro criterio, un pronunciamiento afirmativo".

\subsection{Problema suscitado por la designación de Juez de Policía Local de la I. Municipalidad de Quilicura}

Enseguida nos abocaremos al reclamo de ilegalidad interpuesto por doña M.G. González Danús, ante la I. CAP de Santiago, en contra del Decreto Alcaldicio № 137-94, del 21.04.94, que designó Juez de Policía Local, sin haber convocado y obtenido el acuerdo del Concejo Comunal.

La recurrente hace presente que la alcaldesa rechazó por resolución del 12.05.94, este reclamo en sede administrativa. La afectada hace presente que la alcaldesa designó juez de policía local al abogado don J.A. González Cerón, "sin que hubiera intervenido el concejo municipal, órgano que, conforme a lo expresado por la Ley $\mathrm{N}^{\circ}$ 18.695, integra la Municipalidad".

La alcaldesa expresa en el rechazo del reclamo "que lo practicó en su condición de autoridad facultada para ello, como lo ha dictaminado la Contraloría General de la República, al referirse a nombramientos de jueces de policía local en las comunas de: El Tabo, Licantén, Santo Domingo y otros". La recurrente ante el rechazo del reclamo de ilegalidad en sede administrativa, el 13.05.94, junto con apelar de dicho fallo ante la Corte de Apelaciones, al mismo tiempo, interpuso un recurso de protección, con el Rol № 1.310-94, el que le fuera rechazado por la Corte en resolución del 08.06.94.

En el considerando cuarto, la Corte expresa: "Que luego, a la fecha antes referida $-08.08 .63-$, el municipio se hallaba conformado por un cuerpo colegiado de 'regidores', que salvas las excepciones legales, elegían al Alcalde, como representante legal de la 'Municipaldad'. De consiguiente, el artículo $4^{\circ}$ de la Ley № 15.231 , al disponer que este último órgano debía hacer la designación de Juez de Policía Local, se remitía indudablemente, a ese 
órgano colegiado, compuesto por los regidores, de los cuales uno de ellos, era elegido por sus pares como Alcalde". A continuación, en el considerando quinto, se dice: "Que la Constitución Política en actual vigencia, no alteró sustantivamente esta situación. Su artículo 107, dice que 'La administración local de cada comuna... reside en una municipalidad, la que está constituida por el alcalde que es su máxima autoridad, y por el concejo comunal respectivo. En la mayoría de los casos, además son los miembros de ese Concejo, los que 'eligen' al alcalde. De este modo puede observarse que el organismo que nos ocupa, ha mantenido una tradición jurídica en su conformación, que se arrastra por largos años en la historia de la República. La 'municipalidad' fue y sigue siendo un órgano compuesto por un sector colegiado: los integrantes del concejo municipal y otro unipersonal, el alcalde, que lo preside".

$\mathrm{E} 1$ considerando duodécimo, dice: "Que resulta forzoso para esta Corte, por consiguiente, entender que el proceder de la Municipalidad recurrida -Quilicura-, de la representación anotada, no se ha ajustado a los textos legales que rigen la materia y que, por ende, ha incurrido en la ilegalidad denunciada. El examen de la situación, formulado por la Contraloría General de la República en su pronunciamiento № 4.066 de 04.02.94, relativo al nombramiento de Juez de Policía Local en la comuna de Licantén, que sirve de apoyo a la argumentación de la recurrida - I. Municipalidad de Quilicura - no profundiza en el tema, dando preeminencia en su examen a la normativa de la Ley № 18.695 y, en definitiva, sólo tiene un valor informativo para este Tribunal. Por otra parte, el examen de legalidad y constitucionalidad hecho por el mismo órgano, con motivo de la toma de razón del decreto de nombramiento del magistrado señor González Cerón, no es bastante consideración, para esta Corte, para influir en la decisión de este recurso".

En el considerando decimocuarto, se dice: "Que del examen de los antecedentes documentales acompañados por la recurrente -M.F. González Danús-, es dable observar la existencia de sendas sentencias recaídas en recursos de protección, libradas por las Cortes de Apelaciones de Iquique y Puerto Montt, los días 10.11 .93 y 31.05.94, respectivamente; ambas atinentes a la materia que en esta acción es objeto de recurso de ilegalidad. Las argumentaciones contenidas en esos fallos, son análogas a las que se vierten en éste y ambas sentencias al ser apeladas por los afectados, fueron confirmadas por la Excma. Corte Suprema". "Por estas consideraciones y visto lo dispuesto en los artículos $6^{\circ}, 7^{\circ}$ y 107 de la Constitución Política de la República, artículos $4^{ }$y $8^{\circ}, 55,56,57,58,59,69$ y 136 de la ley № 18.695 , SE ACOGE el presente recurso de ilegalidad interpuesto en autos en contra de 
la Municipalidad de Quilicura, representada por su alcaldesa, doña C. Romo S., y se declara que se invalida el Decreto Alcaldicio № 137-94, de 21 de abril del año pasado, por el que se nombró titular del Juzgado de Policía Local de Quilicura a don J.A. González Cerón, debiendo procederse a la designación del magistrado titular de dicho Juzgado en la forma que se ha dejado consignado precedentemente. De conformidad a lo señalado por el artículo 136 letra h) de la ley № 18.695, se declara, además, que la recurrente -M.F. González- tendrá derecho al cobro de los perjuicios que el proceder de la Municipalidad recurrida -Quilicura- le hubieran significado. Finalmente, no se enviarán estos antecedentes al Juzgado del Crimen respectivo, por no aparecer de ellos, que se hubiera incurrido en delito". Rol № 2.429-94.

\section{CONCLUSION}

Del análisis doctrinario que hemos efectuado y de su aplicación al problema de interpretación jurídica realizada en la presente monografía, ha quedado en claro el procedimiento que debe seguirse para designar a los Jueces de Policía Local. En primer término se han demostrado las consecuencias jurídicas derivadas de la posesión efectiva de la investidura regular, requisito que es esencial para dar validez a las resoluciones y sentencias dictadas por dichos magistrados; la exigencia constitucional de la investidura regular se extiende a todos los funcionarios que ejercen potestades o atribuciones de derecho público, sin excepción. Ha quedado en evidencia, de manera incuestionable, que la falta de investidura regular produce, necesaria e inevitablemente, la nulidad de los actos. Cuando hablamos de los "actos" no nos referimos solamente a los actos judiciales, sino que, también, a los actos administrativos y a los legislativos y de gobierno.

En la designación de cualquier funcionario, entre los que se incluye a los Jueces de Policía Local, debe respetarse el supraprincipio de juridicidad, que ordena la Constitución Política en sus artículos $6^{\circ}$ y $7^{\circ}$, entre otros allí contenidos, debido a que es, ordinariamente a través de aquellos como se ejercen las potestades públicas surgidas de la soberanía nacional Art. $5^{\circ}$ C.P. También hemos demostrado doctrinariamente, de manera congruente con el derecho positivo que los órganos superiores de una municipalidad son el Alcalde y el Concejo, las atribuciones que la Constitución otorga a este último son normativas, resolutivas y fiscalizadoras, y que los ejemplos dados al respecto por la Carta Fundamental, no constituyen una norma de clausura que los prive de su deber de intervenir en otros actos, en que leyes especiales, 
confieren al municipio, sin haber excluido expresamente al Concejo. Nuestra posición doctrinaria, basada en el estudio de las normas y principios constitucionales y de su aplicación a los órganos de la Administración del Estado, entre los que figuran las muncipalidades, también ha sido seguida por la jurisprudencia, la cual, en esta materia, ha diferido del criterio sustentado en los dictámenes emitidos por la Contraloría General de la República. Confiamos en que lo expresado en esta monografia ayudará eficazmente a la solución del error interpretativo en que se ha incurrido en la designación de los Jueces de Policía Local. 